\title{
RESENHA
}

\author{
Jander Luiz Rama
}

\section{Apontamentos sobre philosophy of tecnology: the technological condition: an anthology}

\section{Resumo}

Apontamentos sobre Philosophy Of Technology: The Technological Condition - An Anthology, uma coletânea de artigos acadêmicos dedicada à filosofia da tecnologia, editada por Robert C. Scharff e Val Dusek.

\section{Palavras-chave}

Tecnologia. Filosofia. Arte contemporânea. 
A ciência e a tecnologia, enquanto assunto e meio, estão presentes em diversas obras de arte e refletem a própria condição humana frente à crescente velocidade das mudanças causadas pelos avanços tecnológicos, especialmente nas últimas décadas. Obras de artistas como Stelarc, Nam June Paik, Eduardo Kac ou Chris Burden relacionam diversos pontos presentes na alta tecnologia com suas problemáticas implicações nos afazeres e na natureza humana.

Como exemplo, as performances e próteses de Stelarc buscam modos inventivos para integrar o corpo estranho tecnológico ao próprio corpo humano. De modo semelhante, Paik elabora parafernálias tecnológicas como corpos artificiais, robôs, em busca de outros significados para as imagens de seus vídeos. Lidando com inteligentes proposições, a partir de mecanismos de uma cidade fictícia, Metropolis II, ou com um coelho transgênico, GFP Bunny, Burden e Kac dialogam com problemáticas que tangenciam grandes temores da humanidade, como o ritmo alucinante das máquinas aplicado ao tecido urbano e a engenharia genética aplicada a produtos alimentícios e farmacêuticos.

De modo tão impactante como a velocidade dos avanços tecnocientíficos, estas obras confrontam-nos a buscar reflexões mais elaboradas de diversos níveis sobre esta presença incontestável. As implicações da tecnologia avançada não são neutras na sociedade em geral, nem apolíticas e, muito menos, acríticas. As discussões surgidas desde o princípio, em que o homem se utiliza da tecnologia para sobrepujar os limites físicos de sua natureza, alcançam novo patamar na atualidade.

Tomando um caso específico do cotidiano recente, especialistas da área de tecnologia e líderes de laboratórios de robótica vem preocupando-se com as aplicações nocivas de Inteligência Artificial (IA) em mecanismos bélicos e estratégias de combate armado. Em 2017, um grupo de renomados técnicos e peritos no assunto redigiu uma carta solicitando à ONU que inclua a IA, aplicada em combate, na lista de armamentos banidos (CCW). Segundo afirmam, se tal ferramenta tecnológica for aplicada à guerra, parte da humanidade corre risco frente à eficiência da máquina nas mãos de ditadores, terroristas ou mesmo hackers.

Com questões pertinentes à arte ou ao cotidiano, a tecnologia avançada e suas implicações podem ser melhor discutidas no âmbito da filosofia da tecnologia. Se o século XX foi palco de diversas discussões motivadas por questões 
éticas envolvendo o desenvolvimento tecnológico, sua aplicação na guerra e na sociedade, neste terceiro milênio, estas questões ganham outra dinâmica, envolvendo novos fenômenos nos debates filosóficos relacionados à benéfica/ problemática inserção da técnica nas relações e afazeres humanos. A produção de alimentos, as redes sociais, a robótica e automação, a engenharia genética, dentre outras, gera inúmeras reflexões e não podem ser tratadas apenas como saberes práticos. Mesmo havendo posições tão opostas que podem originar a tecnofobia ou a tecnofilia, há a necessidade de se debater as nuances sobre as aplicações tecnológicas e seus efeitos em distintas áreas do desenvolvimento humano. Como afirma Walter Brugger:

Neste particular, se por um lado se manifesta o poder benéfico da técnica, sem a qual não teria sido possível que a humanidade e sua cultura alcançassem o atual grau de desenvolvimento, por outro lado não se pode desconhecer uma série de consequências indesejáveis, que evidentemente não brotam, em sua totalidade, da essência da técnica, mas, amiúde, de sua defeituosa inserção no domínio global da vida. ${ }^{1}$

A obra organizada por Robert C. Scharff e Val Dusek em 2003, e reeditada em 2014 ( $2^{\mathrm{a}}$ edição), intitulada Philosophy of Technology: The Technological Condition: an Anthology aborda material exaustivo sobre as principais vertentes da filosofia da tecnologia.

A antologia de Scharff e Dusek está dividida em seis partes distintas: Part I The Historical Background, Part II - Philosophy, Modern Science, and Technology, Part III - Defining Technology, Part IV - Heidegger on Technology, Part V - Technology and Human Ends e Part VI - Technology as Social Practice. Esta divisão é muito bem-vinda, pois organiza os filósofos clássicos e suas abordagens sobre o tema e os desdobramentos de questões mais específicas a partir de pensadores da atualidade.

A primeira edição deste compilado, publicado em 2003, cresceu a partir das necessidades e experiências dos editores como professores de filosofia da tecnologia. Esta segunda edição leva em conta novas abordagens frente a este campo relativamente novo da filosofia. Apesar do número de antologias deste tipo ter crescido, esta é muito pertinente na abordagem de questões cruciais da filosofia da tecnologia.

Segundo os autores, o objetivo da Part I foi o de proporcionar um compilado de alguns discursos familiares na tradição filosófica ocidental, cujos pontos de vista sobre a relação entre o conhecimento e as suas aplicações têm desempenhado um papel importante na criação de um contexto herdado, dentro do qual a filosofia contemporânea da tecnologia leva em consideração. Esta seleção foi concebida para encorajar a análise da questão de o porquê, em comparação a outros temas filosóficos, a filosofia da tecnologia é relativamente recente em sua origem.
1. BRUGGER, 1962, p.400. 
A Part II contém leituras contemporâneas que, especialmente, enfatizam e avaliam criticamente os pressupostos básicos que nos foram transmitidos a partir do século XIX sobre: ciência; a relação entre a ciência moderna e a tecnologia; e o tratamento adequado da filosofia em ambos. Ainda aborda uma breve história da ascensão e do declínio do positivismo lógico, ou Círculo de Viena, da filosofia da ciência, juntamente com o surgimento de várias críticas pós-positivistas e alternativas.

Os textos da Part III destacam as questões relativas à tentativa de definir a tecnologia, bem como estas definições permanecem instáveis e pluralistas. Muitos dos recentes esforços para definir a tecnologia ainda tendem, deliberada ou involuntariamente, a posições sobre dois temas polêmicos, ou seja: se e como a ciência moderna transformou tecnologias pré-científicas; e se a tecnologia é essencialmente ciência aplicada.

$O$ ensaio de Part IV trata das impressões de Martin Heidegger em seu escrito $A$ questão da técnica, e uma amostragem de respostas a ele. 0 ensaio de Heidegger apresenta o que é provavelmente a mais influente, embora não significando a mais popular posição no campo.

Na Part $V$, as leituras levantam um conjunto de questões gerais sobre o papel adequado da tecnologia na mediação de nossas relações com o mundo natural. Uma seção considera a questão de saber se os seres humanos são essencialmente usuários de ferramentas e, portanto, suscetíveis às problemáticas tecnológicas somente quando estão envolvidos em atividade de cunho tecnológico. A segunda seção questiona, como alguns escritores têm argumentado, se a influência da tecnologia em nossas vidas pode ser forte e penetrante a tal ponto que opera como uma força autônoma e faz todo o discurso otimista de "controle" parecer ingênuo. Os ensaios na terceira seção estabelecem relações entre natureza humana e o poder tecnológico, abordando a questão ecológica. Também debatem sobre a legitimidade do famoso imperativo baconiano que encoraja a pensar em "conhecimento", principalmente como aquilo que nos dá o poder de controlar nosso ambiente natural.

A Part VI concentra-se em questões que surgem quando a tecnologia é vista, não tanto como uma expressão da natureza humana ou como um instrumento para controlar a natureza, mas sim como uma definição específica e cada vez mais dominante das práticas socioculturais. Os ensaios na primeira seção tratam da mediação da tecnologia na maioria de nossas relações, não apenas com a natureza, mas também entre nós. Em Technology and Cyberspace, na segunda seção, vários autores consideram a intrigante questão de saber se a revolução cibernética promete alterar as noções básicas de quem somos, do que é a mente ou consciência e o que é a experiência da realidade. A terceira 
seção traz como foco uma questão implícita em muitas outras leituras, a saber, quais são as implicações para o futuro da política e da democracia na nossa prática social e suas formas cada vez mais tecnológicas.

Chamo a atenção para o capítulo que trata da obra de Heidegger (Part IV - Heidegger on Technology), articulando mais especificamente A questão da Técnica, da década de 1950, com outros quatro textos atuais. Confrontando as principais ideias de Heidegger, Comte e Borgmann, os autores do capítulo, como Scharff e Feenberg, trazem elementos importantes para o debate sobre a tecnologia avançada em nossa sociedade.

Enfim, diversos textos inseridos nestas seis partes apresentam distintos posicionamentos filosóficos da tecnologia, trazendo farto material que pode nutrir argumentos relativos a diversas questões e envolvendo a tecnologia na atualidade, bem como oxigenam debates acerca de produções artísticas da contemporaneidade que igualmente lidam com a tecnologia enquanto meio e assunto.

\section{REFERÊNCIAS}

BBC Brasil. Líderes em tecnologia pedem proibição de 'robôs assassinos'. Disponível em: <http://www.bbc.com/ portuguese/geral-40997536>. Acessado em: 21 ago. 2017.

BRUGGER, Walter. Dicionário de filosofia. São Paulo: Herder, 1962.

SCHARFF, Robert C.; DUSEK, Val. Philosophy of Technology: The Technological Condition : an Anthology. $2^{\mathrm{a}}$ ed. Oxford: Blackwell, 2014.

\section{Jander Luiz Rama}

Artista visual e doutorando em Poéticas Visuais pelo PPGAV-UFRGS. É mestre em Poéticas Visuais pela mesma instituição. Tem publicado artigos, participado de editais, realizado numerosas exposições e recebido prêmios como a Bolsa Iberê Camargo - Ateliê de Gravura (2013), Prêmio IEAVI (2014), Prêmio Açorianos - destaque em gravura (2014) e Prêmio Incentivo à Criatividade do $21^{\circ}$ Salão CMPA (2016). Participa do grupo de pesquisa Expressões do Múltiplo CNPq-UFRGS.

(*) Texto submetido em setembro de 2017. 